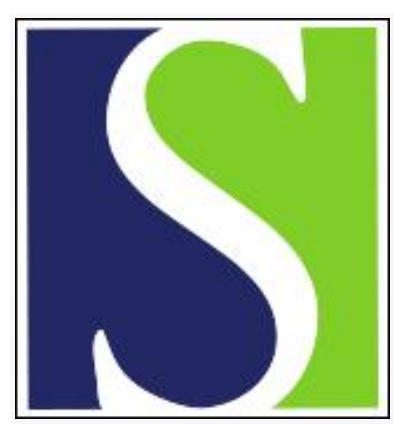

Scand J Work Environ Health 1986;12(6):574-581

https://doi.org/10.5271/sjweh.2100

Issue date: Dec 1986

\title{
Impaired odor perception in tank cleaners.
}

by Ahlstrom R, Berglund B, Berglund U, Lindvall T, Wennberg A

This article in PubMed: www.ncbi.nlm.nih.gov/pubmed/3823805 


\title{
Impaired odor perception in tank cleaners
}

\author{
by Richard Ahlström, MSc, ${ }^{1}$ Birgitta Berglund, $\mathrm{PhD},{ }^{1}$ Ulf Berglund, PhD, ${ }^{2}$ Thomas Lindvall, MD, ${ }^{3}$ \\ Arne Wennberg, $\mathrm{MD}^{4}$
}

\begin{abstract}
AHLSTRÖM R, BERGLUND B, BERGLUND U, LINDVALL T, WENNBERG A. Impaired odor perception in tank cleaners. Scand J Work Environ Health 12 (1986) 574-581. The olfactory perception of 20 men (tank cleaners) exposed to petroleum products (while cleaning oil tanks) was examined. Office workers and watchmen were used as referents $(\mathrm{N}=20+20)$. They were matched with regard to sex, age, and smoking habits. Odor detection thresholds and the perceived odor intensity of four odorous stimuli, pyridine, dimethyl disulfide (DMDS), n-butanol, and heating oil vapor (gas phase of heating oil heated to $+40^{\circ} \mathrm{C}$ ), were determined. The results suggested that the tank cleaners had higher absolute odor thresholds for n-butanol and oil vapor than the referents. The psychophysical function of the tank cleaners and referents differed for all the tested substances in respect to odor intensity. The tank cleaners displayed an odor deficit analogous to the hearing loss known as "loudness recruitment," ie, normal perception of strong stimuli but impaired perception of weak stimuli. This odor deficit was therefore named "odor intensity recruitment" and seems, in tank cleaners, to be associated with occupational exposure to oil vapor.
\end{abstract}

Key terms: absolute thresholds, dimethyl disulfide, heating oil, n-butanol, odor deficit, olfaction, pyridine, recruitment, solvents.

Both aliphatic and cyclic hydrocarbons may have neurotoxic effects. Those effects, as exerted by organic solvents with neurotoxic properties known since the middle of the last century, have been the subject of extensive study in recent years. The early literature contains a great many accounts of chronic symptoms indicative of more or less permanent damage to the nervous system (18). One latter-day study involved a comprehensive investigation of the effects on the nervous system of car and industrial spray painters as a result of long-term exposure to relatively low concentrations of solvent mixtures (8). It revealed effects on a number of functions, effects pointing to involvement of both the central and peripheral nervous systems.

When air containing solvent is inhaled, the respiratory mucosa is continuously exposed to a relatively large amount of solvent. This solvent is resorbed to some extent, mainly in the lungs, but even in other parts of the respiratory mucosa. The nasal part of this mucosa contains cells (olfactory cells) with the same structure and basic function as cells in the nervous system.

1 Department of Psychology, University of Stockholm, S-106 91 Stockholm, Sweden.

2 Royal Institute of Technology, S-100 44 Stockholm, and National Institute of Environmental Medicine, S-104 01 Stockholm, Sweden.

3 Karolinska Institute, S-104 01 Stockholm, and National Institute of Environmental Medicine, S-104 01 Stockholm, Sweden.

4 Department of Occupational Neuromedicine and Research Department, National Board of Occupational Safety and Health, S-171-84 Solna, Sweden.

Reprint requests to: Dr A Wennberg, Department of Occupational Neuromedicine, National Board of Occupational Safety and Health, S-171 84 Solna, Sweden.
The distribution of solvent in the body depends to some extent on the air : blood distribution coefficient (about 10) and the corresponding coefficient for blood and other organs. For example, the blood:brain distribution coefficient is 3 (17). So the solvent concentration may be about 30 times higher in the brain than in the air inhaled by the exposed subject. However, a long period of exposure is required if this is to be the case, and equilibrium ultimately ensues. Olfactory receptor cells are affected by a high concentration right from the first breath, so they must be regarded as a vulnerable part of the nervous system, even if solvent concentration in the brain could be higher, in theory, under certain conditions.

Studies on rat have shown that olfactory exposure to a low concentration of a number of substances in an otherwise odor-deficient environment leads to morphological degeneration of the brain's olfactory bulb $(5,14,20)$. The sensitivity of the experimental animals to substances to which they were exposed was not impaired. But sensitivity to other, but similar, substances to which they had not been exposed was depressed. This effect has been interpreted as a result of sensory deprivation rather than that of overexposure, ie, understimulation in terms of odors in the environment of the experimental animals in this instance. On the basis of this assumption, we felt that a study of the sense of smell of people occupationally exposed to organic solvent vapor might be of some interest.

Ekblom and co-workers (7) applied a similar reasoning in their studies on the effects on the sense of smell of frogs after exposure to organic solvents. They studied the effects of toluene, styrene, xylene, trichloroethylene and white spirit. The exposures were rather brief (maximum $90 \mathrm{~min}$ ) and of rather high con- 
centrations, up to more than 20 times the occupational exposure limit. They found clear damage to the olfactory cells for several of the mentioned solvents. These results are of course not applicable to humans exposed long term during their daily work. However, they clearly indicate that the olfactory cells might be sensitive to solvent exposure and motivate further studies on workers exposed to solvent vapors.

After a number of spontaneous complaints about an impaired sense of smell had been made by people whose work involved cleaning oil tanks, we decided that a study of the sense of smell of a group of subjects from this occupational category was warranted. For a general survey of previous studies of the sense of smell, see the report of Engen \& Mair (11).

\section{Subjects and methods}

\section{Examined groups}

A group of 20 men from 26 to 62 years of age who were employed by decontamination companies in the Stockholm area were selected for the study. Their work entailed removing sludge at the bottom of oil tanks and subsequently cleaning the tank interiors. The sludge consists of oil, slurry, and water condensate. The heavy oil in oil tanks is heated with heating coils, so the air temperature in tanks often rises to uncomfortable levels. Walls, beams, and stanchions are scraped with simple hand scrapers, and the viscous, watery residue on the floor is scraped over to a suction hose with large, long-handled scrapers. This work is physically strenuous and causes breathlessness and high energy consumption. The emptying and cleaning of a tank takes one-half to two days, depending on the tank size. Breaks are taken when required, usually when the heat becomes too uncomfortable, but sometimes because of dizziness, nausea, or finger tingling, ie, symptoms which may be due to the acute effect of solvent on the nervous system. During the work, personal safety equipment was used, ie, cotton overalls, rubber boots, and rubber gloves. A mask was seldom used.

The selection criteria for the 20 tank cleaners were (i) tank cleaning work for a total of at least two years and (ii) at least one tank cleaning in the past six months.

Two reference groups, each matched with the tank cleaners with respect to sex, age ( \pm 2 years), and smoking habits (smoker/nonsmoker), were recruited from oil company officers and security guards. Each tank cleaner participated in the olfactory tests on the same day as his matched referent from reference group 1.

Before participating in the study, all the subjects were presented an extensive questionnaire concerning medical history (ie, head injury, drug consumption), work conditions, and living habits. As no differences were found in this respect between the groups, they were considered comparable for this study.
Before each experimental session, the subjects were asked about acute respiratory disorders (allergic or infectious) in order to exclude conditions that may affect odor perception.

\section{Occupational hygiene measurements}

The circumstances prevailing in exposure to hydrocarbons during tank cleaning work were studied from measurements made with seven of the 20 subjects in the exposed group. They carried out a total of 10 tank cleanings (two small home tanks containing light fuel oil and eight large industrial tanks containing heavy oil. The effective cleaning time in the tanks was less than $30 \mathrm{~min}$ in the home tanks and 33 to $72 \mathrm{~min}$ in the large tanks.

The measurements were made with personal sampling equipment. Vapor was collected in graphite tubes from which it was subsequently extracted and analyzed with an infrared spectrophotometer according to the Swedish standard (4).

Table 1 shows that hydrocarbon concentrations were higher in the cleaning of heavy-oil industrial tanks than in the cleaning of home-fuel oil tanks. The difference was probably due to the fact that heavy oil, which is highly viscous at room temperature, must be handled in a heated state and is thereby vaporized to a greater extent. The time consumed in cleaning heavy-oil tanks was also longer than for the home-oil tanks, not merely because the former were larger but also because the higher temperature reduced work capacity and made the insertion of brief pauses necessary.

There are no occupational standards for heating oils in the Swedish list of occupational standards (24). That for $\mathrm{n}$-decane can serve as guidance however. It has a limit value of $500 \mathrm{mg} / \mathrm{m}^{3}$ and a maximum allowable concentration of $625 \mathrm{mg} / \mathrm{m}^{3}$. Fuel oils largely consist of paraffin hydrocarbons. The heavy oil used for the olfactometric tests in this study probably contained hydrocarbons in the $\mathrm{C} 13-\mathrm{C} 18$ interval.

Table 1. Exposure to hydrocarbons during the cleaning of tanks containing different types of fuel oils - Time-weighted values.

\begin{tabular}{cccc}
\hline $\begin{array}{l}\text { Fuel oil } \\
\text { type }\end{array}$ & $\begin{array}{c}\text { Hydrocarbon } \\
\text { content } \\
\left(\mathrm{mg} / \mathrm{m}^{3}\right)\end{array}$ & $\begin{array}{c}\text { Temperature } \\
\left({ }^{\circ} \mathrm{C}\right)\end{array}$ & $\begin{array}{c}\text { Sampling } \\
\text { duration } \\
(\mathrm{min})^{\mathrm{b}}\end{array}$ \\
\hline 1 & 285 & 21 & 25 \\
1 & 255 & 16 & 29 \\
3 & 720 & 35 & 61 \\
3 & 1600 & 32 & 59 \\
4 & 705 & 34 & 59 \\
4 & 1615 & 43 & 45 \\
4 & 250 & 32 & 33 \\
4 & 440 & 36 & 72 \\
4 & 240 & 36 & 55 \\
4 & 395 & 36 & 49 \\
\hline
\end{tabular}

a Type according to Swedish standard (type $1=$ light heating fuel used for small houses, types 3 and $4=$ heavy oil used for factories)

b The number of samples per sampling session $=2-4(15-25$ min per series). 


\section{Odor perception measurements}

The studies were conducted in a laboratory especially designed for olfactory investigations (16). Its experimental chamber was equipped with two exposure hoods with openings for the subject's nose and mouth. The design of the hoods and the high rate of airflow in them $(100 \mathrm{l} / \mathrm{min})$ made it possible for subjects to take large sniffs without encountering perceptible resistance.

All the subjects in the exposed and reference groups were examined with respect to their ability to detect odor (absolute odor threshold) and to scale odor intensity (magnitude estimation). Four test odors (odor stimuli) were used in the study.

Odor stimuli. The four test substances used in the study were pyridine (Merck, analytical grade), n-butanol (Merck, analytical grade), dimethyl disulfide (Merck, analytical grade), and oil vapor (the gas phase of heated heavy oil). They were selected on the basis of their various properties as regards odor and assumed effect on the nasal mucosa.

Pyridine and dimethyl disulfide have a disagreeable odor. Pyridine is also an irritant; therefore it elicits activity conducted via the trigeminal nerve (10), apart from stimulating olfactory cells.

$n$-Butanol can be regarded as having a relatively pleasant smell, at least at concentrations below the limit value. Another reason for including $n$-butanol is that it has been selected as a reference substance for the standardization of odor intensity measurements (19).

We also wished to test a complex gas mixture which was representative of gas encountered in oil tank environments and selected the vapor phase of heavy oil from a heated experimental oil tank (size $3 \mathrm{~m}^{3}, 50 \%$ filled with oil heated to $+40^{\circ} \mathrm{C}$ ). The vapor was as-

Table 2. Concentrations of odorous substances used in the threshold and odor intensity determinations. ${ }^{a}$

\begin{tabular}{crrrr}
\hline \multirow{2}{*}{$\begin{array}{l}\text { Step } \\
\text { number }\end{array}$} & \multicolumn{4}{c}{ Odorous substance } \\
\cline { 2 - 5 } & Pyridine & $\begin{array}{l}\text { Dimethyl } \\
\text { disulfide }\end{array}$ & n-Butanol & Oil vapor \\
\hline & 4 & 4 & 10 & 2 \\
1 & 8 & 8 & 20 & 4 \\
2 & 12 & 12 & 30 & 5 \\
3 & 16 & 16 & 40 & 8 \\
4 & 24 & 24 & 60 & 21 \\
5 & 64 & 64 & 160 & 45 \\
6 & 160 & 160 & 400 & 105 \\
7 & 431 & 431 & 1120 & 223 \\
8 & 1145 & 1145 & 2860 & 471 \\
9 & 3026 & 3026 & 7560 & 1000 \\
10 & 3026 \\
\hline
\end{tabular}

a The listed values are targets which were allowed to vary by $5 \%$ at the most during the experiments. The values are stated in parts per billion except for oil vapor, specified as a promille amount of the strongest concentration (step 10), representing a dilution factor of 66 , ie, the number of times the undiluted gas phase was diluted with pure air. Concentration steps 1 to 10 were used in the threshold measure ments. Steps 5 to 10 were used for the odor intensity measurements.

b Four persons with normal olfactory perception participated in a pilot study in which the 10 concentration steps for oil vapor were determined. sayed by gas chromatography (nonpolar glass capillary column, temperature-programmed with $7^{\circ} \mathrm{C} / \mathrm{min}$ from 50 to $290^{\circ} \mathrm{C}$, splitless injection for $1 \mathrm{~min}$, flame ionization detector) and the contents identified by means of mass spectrometry. The most prominent substances were aliphatic hydrocarbons in the C13-C18 range.

Olfactometric system. A high concentration of pyridine, dimethyl disulfide, or $\mathrm{n}$-butanol was formed from the blowing of charcoal-filtered air through a glass flask (thermostate-regulated at $+30^{\circ} \mathrm{C}$ ) containing one of these substances. The different concentrations for each substance were obtained with the aid of steel capillaries of varying length and diameter through which the gas mixture continuously passed to insure a constant flow. For the sampling of oil vapor, charcoalfiltered air (about $200 \mathrm{l} / \mathrm{min}$ ) was blown over the surface of the oil in the experimental tank. A portion of the air-oil vapor produced in this manner was fed into a glass vessel to which dosing capillaries were connected.

By means of a system of magnetic valves, the gas flow from one or more of the capillaries could be injected into the continuous airflow of the exposure hoods. One of the two hoods was used for the oil vapors and the other for the three pure substances. The different concentrations of the pure substances were continuously monitored with the aid of a photo ionization detector (AID Portable Organic Vapor Meter, model 580).

Absolute odor thresholds. There are a number of methods for measuring odor thresholds $(9,16,26)$. The present study employed the method of limits with a concentration series in up to ten steps. The concentrations were selected so that they covered a range from a little less than the anticipated threshold up to a level somewhat below the Swedish occupational standard. For dimethyl disulfide and oil vapor, for which no occupational standards exist in Sweden, a reasonable acceptable level was chosen. The stimulus concentration steps chosen for the experimental substances are listed in table 2 . Since the odor system compresses the signal input, the interstimulus steps were increased with concentration. The choice of the final stimulus concentrations were guided by pilot tests. In the utilized version of the limit method, each stimulus concentration was presented paired with pure, odorless air (blanks). The task of the subject was then to identify the presentation with an odor (16). For each concentration step, the subject had to judge whether or not the two sequential presentations (odor/blank) smelled "alike" ("alike" was also to be the judge when the two presentations were found to lack any smell) or "different." If they were "different," the subject was to report "odor in the first" or "odor in the second" of the two presentations. The paired stimulus presentations con- 
sisted of odor/no odor pairs and no odor/no odor pairs in random sequence. Each subject took part in three presentation series for each odorous substance.

A series was terminated when the subject had reported three correct answers in a row. The presentation sequence for the four test substances was randomized in such a manner that each tank cleaner and his two matched reference subjects received a sequence unique to them. The subjects were instructed to take one or two normal nasal inhalations during each stimulus presentation.

The absolute threshold calculation was based upon the proportion $P$ of the subjects' answers, $P$ being defined as the total number of correct answers $\left(f_{C}\right)$ minus the number of affirmative odor responses when no odor was present, ie, false alarms $\left(f_{F A}\right)$, in proportion to the total number of available answers $\left(f_{C}+f_{F A}\right)$ :

$$
P=\frac{f_{C}-f_{F A}}{f_{C}+f_{F A}} \times 100
$$

equation 1

The absolute group threshold was defined as the stimulus concentration at which the group perceived an odor in $50 \%$ of the cases $(P=50)$, ie, effective dose 50 (ED 50). This value was obtained by fitting a straight line to the $P$ values as a function of the logarithm of the concentration. An interpolation at $P=50\left(\mathrm{P}_{50}\right)$ gave the absolute threshold value.

Perceived odor intensity. The perceived odor intensity was studied in relation to the stimulus intensity. This relationship (the psychophysical function) can be expressed mathematically as a power function with the equation:

$$
R=c S^{n},
$$

equation 2

in which $R$ is the perceived intensity, $S$ stands for the corresponding stimulus intensity, $c$ is a multiplicative constant reflecting the subject's scale unit, and $n$ is an exponent, which is a measure of perceptual sensitivity, that varies for different individuals. For most odorous substances, this exponent is less than one, ie, perceived odor intensity does not increase to the same extent as stimulus intensity $(1,3)$. An important feature of the power function is that it becomes rectilinear in a double logarithmic coordinate system, ie,

$$
\log R=\log c+n \log S . \quad \text { equation } 3
$$

The symbols are the same as in equation 2 .

The method of free number magnitude estimation $(2,23)$ was used in this experiment for measuring perceived odor intensity. With this method subjects assign numerical values to perceived odor intensities in such a manner that the relationship between the numerical values is equivalent to the relationship between odor intensities. Six concentrations (steps $5-10$ in table 2) were selected as stimuli for each of the odorous substances. The lowest of these was above but near the absolute threshold, and the highest slightly below the Swedish occupational exposure limit. In one presentation sequence, all concentrations appeared randomly before each of the six concentrations. Thus each concentration was judged six times by a subject. The rate of presentation was two per minute; therefore each sequence lasted $15-20 \mathrm{~min}$.

The presentation order of the test substances was different for different subjects, but the same for an exposed subject and his two matched referents. They were also assigned the same unique presentation sequence.

\section{Results}

\section{Absolute odor thresholds}

The detection data obtained from the different subjects were treated together in order to obtain one threshold for the exposed and the two reference groups. The group thresholds were corrected for guessing by adjustment for false alarms according to equation 1 . The values calculated in this way are presented in table 3.

The tank cleaners displayed an impaired odor sensitivity to both oil vapor and n-butanol in comparison to their referents. (See table 3.) However, there was no difference in absolute threshold for dimethyl disulfide and pyridine. The threshold values obtained for pyridine, dimethyl disulfide, and n-butanol were within the range of different published thresholds (22). Oil vapor has not previously been studied in this respect. It should be noted that even if the tank cleaners

\begin{tabular}{|c|c|c|c|c|c|c|}
\hline \multirow{2}{*}{ Test substance } & \multicolumn{2}{|c|}{ Exposed group } & \multicolumn{2}{|c|}{ Reference group 1} & \multicolumn{2}{|c|}{ Reference group 2} \\
\hline & $P_{50}$ & $P_{75}-P_{25}$ & $P_{50}$ & $P_{75}-P_{25}$ & $\mathrm{P}_{50}$ & $P_{75}-P_{25}$ \\
\hline $\begin{array}{l}\text { Pyridine } \\
\text { Dimethyl disulfide } \\
\text { n-Butanol } \\
\text { Oil vapor }\end{array}$ & $\begin{array}{l}45.6 \\
13.9 \\
74.6 \\
76.6\end{array}$ & $\begin{array}{r}64.9 \\
41.0 \\
288.3 \\
208.3\end{array}$ & $\begin{array}{l}43.4 \\
13.2 \\
50.5 \\
35.0\end{array}$ & $\begin{array}{r}93.1 \\
27.4 \\
122.3 \\
69.4\end{array}$ & $\begin{array}{l}38.9 \\
20.4 \\
45.2 \\
26.1\end{array}$ & $\begin{array}{l}53.8 \\
49.5 \\
94.8 \\
29.5\end{array}$ \\
\hline
\end{tabular}
in the present study displayed a higher n-butanol

Table 3. Absolute threshold values (at $P_{50}$ ) and length of the interquartile ranges (at $\left.P_{75}-P_{25}\right)^{\text {a }}$

a All values are stated in parts per billion except for those for oil vapor, which are given as the promille value of the strongest concentration employed in the threshold determinations. See footnote a of table 1. 

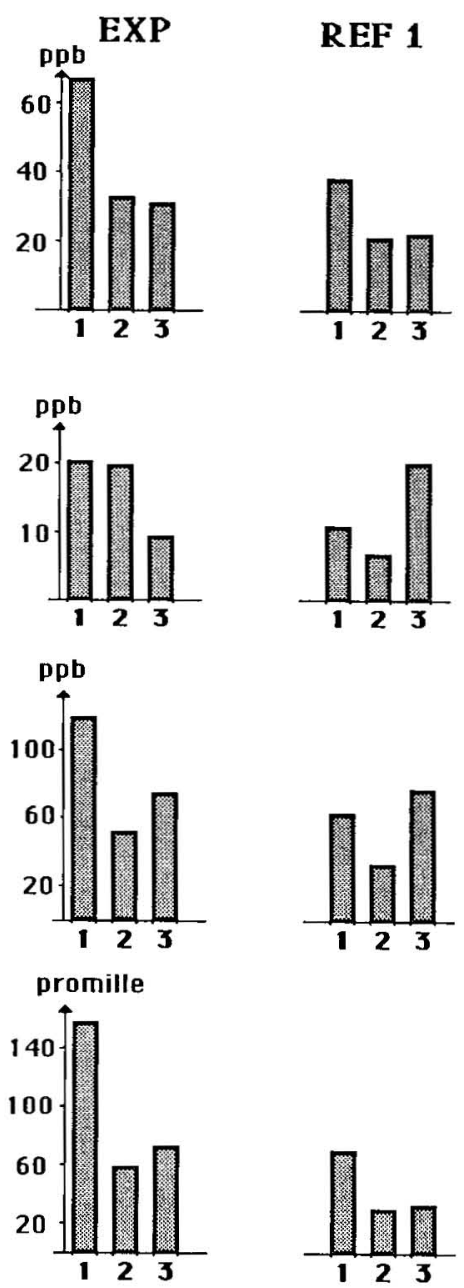

n-BUTANOL

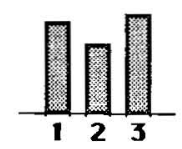

OIL VAPOR
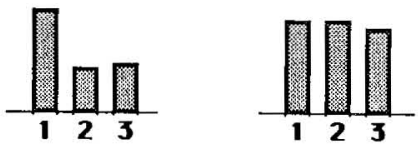

Figure 1. Absolute subgroup thresholds for the exposed $(E X P)$ and reference (REF 1 and REF 2) groups divided into subgroups according to the duration of the exposure-free interval prior to the olfactory test $(1=<1 \mathrm{~d}, 2=1-30 \mathrm{~d}$, and $3=>30 \mathrm{~d})$ (DMDS = dimethyl disulfide)

threshold than the referents, their threshold was still within the normal range. Comparison with other studies may be dubious, since the different methods and olfactometers used may not produce comparable results.

Subdividing the tank cleaners into three groups enabled us to examine whether the elevated odor threshold was related to the length of the period elapsing between the latest exposure and the odor study. The tank cleaners were therefore divided into the following three subgroups according to latest exposure to oil vapors: (i) subjects exposed the day before the olfactory test, (ii) subjects exposed $2-30 \mathrm{~d}$ before the test, and (iii) those exposed more than $30 \mathrm{~d}$ before the test (maximum length $432 \mathrm{~d}$ ). The distribution of age, smoking habits, and number of workdays per year were relatively similar among the subgroups. (See table 4.) However, the total number of years in the profession was somewhat different.
Figure 1 shows the absolute threshold values for the three subgroups of tank cleaners and the corresponding subgroups of referents. The recently exposed tank cleaners (subgroup 1) displayed a higher threshold value for all test substances than the other two subgroups. These results provide some support for the view that the elevated absolute thresholds for the tank cleaners might be an acute effect.

\section{Perceived odor intensity}

The perceived odor intensities were calculated as medians of the 120 judgments for each stimulus concentration and group (six judgments per subject and 20 subjects per group). The median was chosen because of the fairly large number of zero judgments, ie, when subjects were unable to detect any odor even though odor stimulus had been presented. In all but four cases the number of zero judgments was less than $50 \%$. Before the group medians were calculated, the perceived odor intensities for each subject were corrected according to Lane et al (15), ie, the individual grand means were transformed to the grand mean of the group.

The odor intensity scale values (median) of the three groups are shown in figure 2 for each test substance as functions of the stimulus concentration, in log-log coordinates. The figure shows that the psychophysical functions of the reference groups are power functions, since the data fit well to straight lines in a log$\log$ coordinate system. On the other hand, the psychophysical functions of the tank cleaners are, for all test substances, bisected. Their upper segments have slopes which coincide with the power functions of the referents, whereas their lower segments display steeper slopes. The straight lines in figure 2 are fitted to the data by means of the method of least squares (25).

In figure 3 the number of zero judgments is shown as a function of the stimulus concentration for the four test substances. For all four the tank cleaners provided a larger number of zero judgments than the referents at the lowest concentrations. If the zero judgments are excluded from the calculations of the perceived odor intensity scales, the distortion of the psychophysical function is still present in the data of the tank cleaners for all four test substances.

Also for the odor intensity scales, the tank cleaners were divided into the same three subgroups (according to exposure-free days) as for the absolute thresholds. (See table 4.) For pyridine and dimethyl disulfide distorted psychophysical functions were found in subgroup 1 and for n-butanol in subgroups 1 and 2. (See figure 4.) For oil vapor, however, this was true for subgroups 2 and 3 but not for subgroup 1 .

\section{Discussion}

The results of the present study suggest odor threshold elevations for the exposed group, especially for oil vapor and n-butanol. The psychophysical functions of 


\section{PYRIDINE}

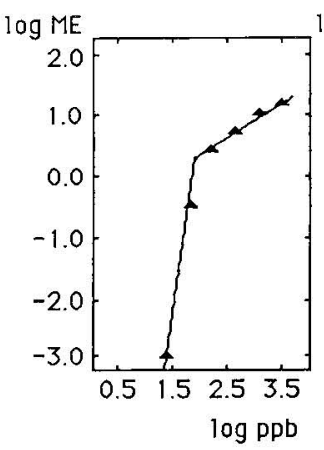

$\log$ ME

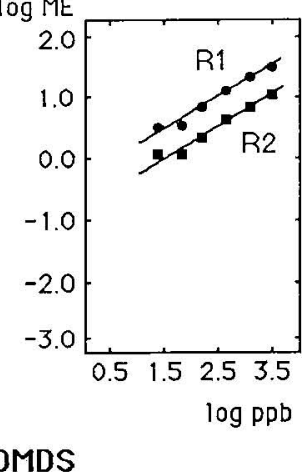

$\log M E$

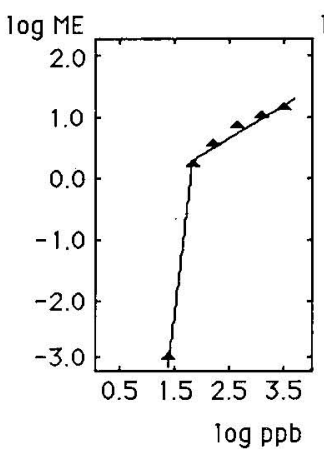

EXPOSED

GROUP

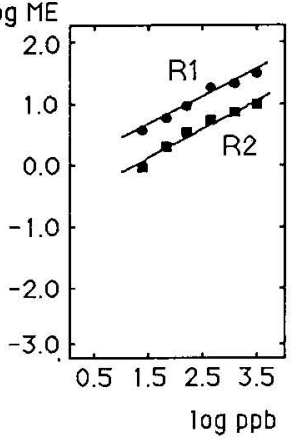

REFERENCE $\log M E$

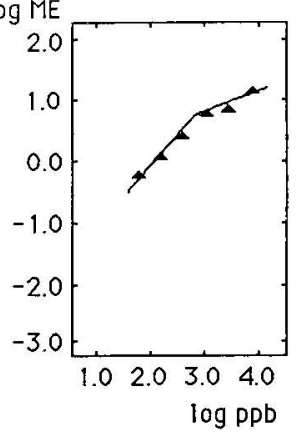

n-BUTANOL

$\log M E$

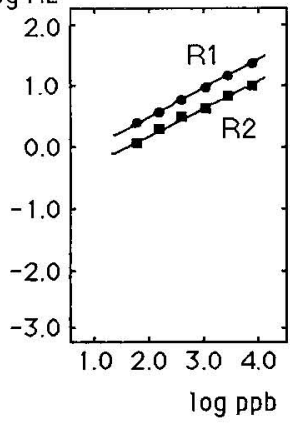

OIL YAPOR

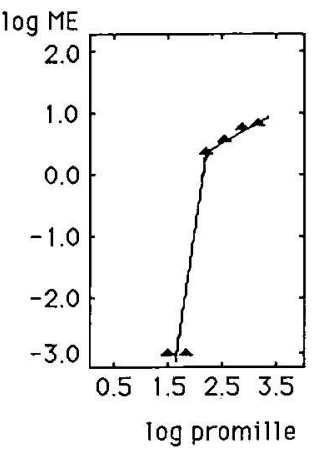

\section{EXPOSED \\ GROUP}

$\log M E$

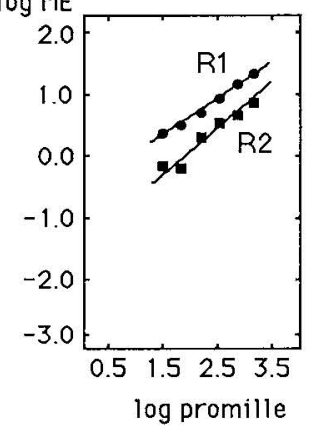

REFERENCE

GROUP 1 AND 2

Figure 2. Psychophysical relationships between perceived odor intensity (ME) and stimulus concentration (parts per billion (ppb) or promille]. (R1 and R2 = reference groups 1 and 2, respectively; DMDS = dimethyl disulfide)

PYRIDINE

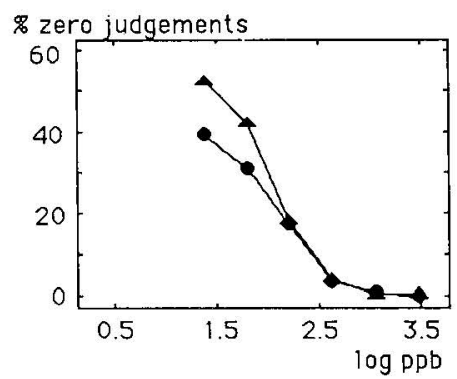

n-BUTANOL

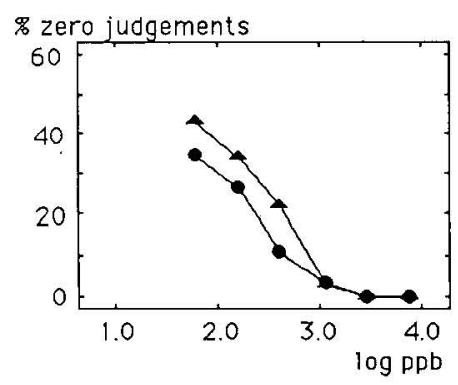

DMDS

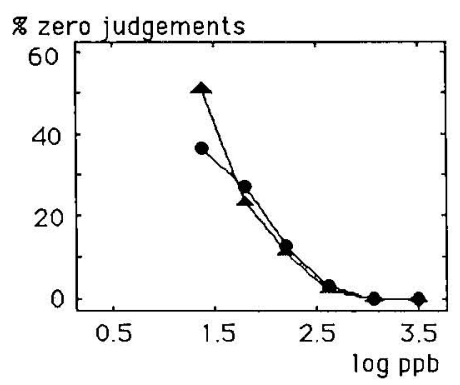

OIL VAPOR

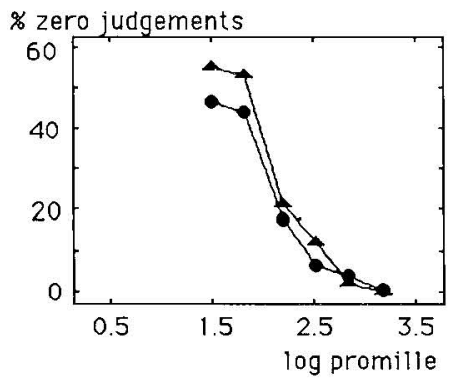

Figure 3. The percentage of zero judgments among the magnitude estimates of the perceived odor intensity plotted against the concentration of the test substance, as expressed on a logarithmic scale (DMDS = dimethyl disulfide, triangles $=$ exposed group, circles $=$ reference groups 1 and 2 combined) 
Table 4. Subdivision of the tank cleaner group with respect to the time (in days) elapsing between the latest tank cleaning and the olfactory test.

\begin{tabular}{lccc}
\hline & $\begin{array}{c}\text { Subgroup 1 } \\
(\mathrm{N}=7)\end{array}$ & $\begin{array}{c}\text { Subgroup 2 } \\
(\mathrm{N}=7)\end{array}$ & $\begin{array}{c}\text { Subgroup 3 } \\
(\mathrm{N}=6)\end{array}$ \\
\cline { 2 - 4 } & & & \\
$\begin{array}{l}\text { Number of } \\
\text { exposure-free days }\end{array}$ & 1 & 11 & $\begin{array}{c}143 \\
\quad \text { Median }\end{array}$ \\
$\quad \begin{array}{l}\text { Range } \\
\text { Median age (years) }\end{array}$ & 1 & $2-30$ & $31-432$ \\
$\begin{array}{l}\text { Median of the length } \\
\text { of employment as a }\end{array}$ & & 35 & 38.5 \\
tank cleaner (years) & 8 & & \\
Number of smokers & 3 & 3 & 11.5 \\
\hline
\end{tabular}

PYRIDINE

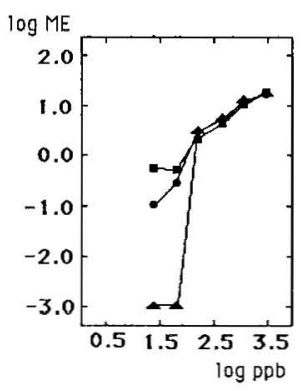

n-BUTANOL

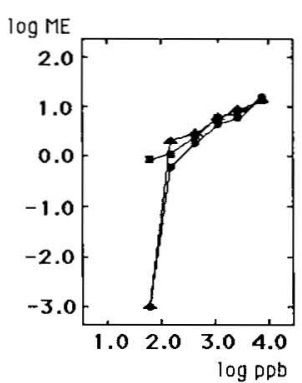

DMDS

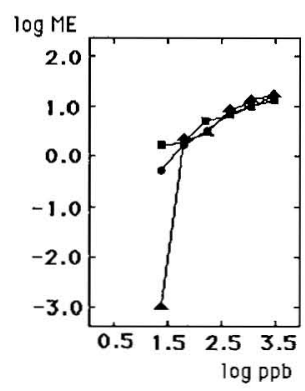

OIL VAPOR

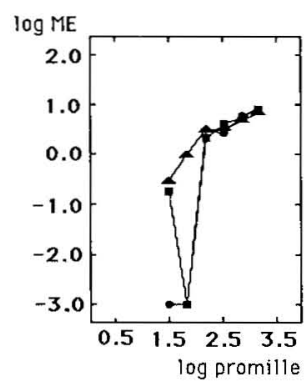

Figure 4. Psychophysical relationships between perceived odor intensity (ME) and stimulus concentration [parts per billion $(\mathrm{ppb})$ or promille] for the tank cleaners divided into subgroups according to the duration of their exposure-free interval prior to the olfactory test. [DMDS = dimethyl disulfide, triangles = subgroup $1(<1 \mathrm{~d})$, circles $=$ subgroup $2(1-30 \mathrm{~d})$ and squares $=$ subgroup $3(>30 \mathrm{~d})$ ]

the exposed group were distorted for all the test substances. The exposed subjects showed markedly lower odor intensity values at the lowest stimulus concentrations than the referents (figure 2). Furthermore they provided a larger number of zero judgments at the lowest concentrations, and this finding indicates an impaired odor sensitivity. It should be noted that, even when the zero judgments are excluded from the calculations of perceived odor intensity, the psychophysical functions of the exposed group still remain distorted (bisected). Bisected psychophysical functions have earlier been shown for subjects with certain types of hearing damage and referred to as "loudness recruit- ment" (21). In analogy, we suggest the term "odor intensity recruitment" for the demonstrated odor perception impairment of the tank cleaners. It is important to remember that a recruitment function may also display patterns other than the bisected function illustrated in figure 2 (13). In the literature on hearing, recruitment is commonly linked to elevated thresholds. However, such a relationship was not consistently found in this study, possibly due to large steps between the concentrations used for the odor threshold determinations.

The comparison with hearing impairment could also be taken a step further. Hearing impairment can affect different frequency ranges. The question then arises as to whether odor intensity impairment displays a corresponding selectivity in respect to the odor spectrum, the term "spectrum" here referring to different types of odors (odor qualities). A study of the entire odor spectrum would obviously be of interest, but such a task is presently not possible in practice. Doty et al (6) has suggested a standardized test, incorporating different odors, for examining large parts of the odor spectrum. A standardization of testing for clinical application is currently in progress (University of Pennsylvania Scratch-n-Smell Identification Test). In the future, it could be used for elucidating the spectral distribution of an olfactory deficiency.

The fact that we found a deficit in odor perception in the exposed group for all the tested substances points to a general system effect rather than to a specific receptor effect. This general effect could be restricted to the nasal mucosa, but it may also involve other parts of the nervous system, either in the olfactory part, at a central level, or in other associated parts of the central nervous system. Such a central effect might follow a pulmonary uptake of the oil vapor.

Morphological studies of the sense of smell in rats have disclosed that olfactory receptor neurons are normally subject to continuous renewal. The renewal time and life time of these neurons have been found to be $15-20 \mathrm{~d}$ and $30 \mathrm{~d}$, respectively (12). Thus the sense of smell differs from other parts of the nervous system, where no neuronal renewal is known. If a similar renewal prevails in humans, it might interfere with the interpretation of the present findings, both concerning the question of chronic or acute effects and their location in the nervous system. Even if a part of our findings could be explained by acute effects, the possibility of odor intensity recruitment becoming chronic over a long period of time should not be ignored.

One interesting finding is that, for oil vapor, an odor intensity recruitment was likely in subgroups 2 and 3 (no occupational exposure to oil vapors during the last $24 \mathrm{~h}$ ) but not subgroup 1, which was exposed on the day before the olfactometric test. This finding indicates that the odor intensity recruitment might be a permanent effect that can be disguised by normal sensory adaptation to acute exposure. 


\section{Conclusions}

The experimental results suggest that the exposed group (tank cleaners) had higher odor thresholds than the reference groups for $\mathrm{n}$-butanol and oil vapor and displayed an impaired odor sensitivity for all four test substances (pyridine, dimethyl disulfide, n-butanol, and oil vapor) in the form of "odor intensity recruitment."

It should be noted that the largest differences in olfactory sensitivity between tank cleaners and referents were found for oil vapor. This finding supports the suspicion that prolonged occupational exposure to oil vapor is accompanied by adverse effects on odor perception.

The odor perception deficits demonstrated among the tank cleaners seem to be wholly or partially acute (ie, transient) since they in general were most salient among those tank cleaners occupationally exposed to oil vapor within the last $24 \mathrm{~h}$.

\section{Acknowledgments}

This work was sponsored by the Swedish Council for Research in the Humanities and Social Sciences and the Swedish Work Environment Fund (ASS 81-0139).

We wish to thank the Occupational Health and Safety Service of the Transport Trades in the Stockholm area, especially $\mathrm{H}$ Åström and M Wallin, for valuable cooperation.

\section{References}

1. Berglund B, Berglund U. Human olfactory perception of environmental chemicals. In: Norris DM, ed. Perception of environmental chemicals. Elsevier, Amsterdam 1980, pp 81-101.

2. Björkman M, Ekman G. Experimentalpsykologiska metoder [Psychological experimental methods]. Almqvist \& Wiksell, Stockholm 1957.

3. Cain WS, Engen T. Olfactory adaptation in the scaling of odor intensity. In: Pfaffman $\mathrm{K}$, ed. Olfaction and taste III. Rockefeller University Press, New York, NY 1969 , pp 127-141.

4. Commission for Standards in Sweden. Luft på arbetsplatser - Bestämning av masskoncentration av kolväte (IR-metod) [Air at workplaces - Estimation of mass concentration of hydrocarbons (IR method)]. Stockholm 1978. (Swedish standard SS 028411).

5. Döving KB, Pinching AJ. Selective degeneration of neurons in the olfactory bulb following prolonged odour exposure. Brain Res 52 (1973) 115-129.

6. Doty R, Sharman P, Krefetz D, Dann M. Recent progress in the development of a clinically useful microencapsulated olfactory function test. In: Surjan L, Bodo GY, ed. Proceedings of the XIIth OLR World Congress. Budapest (Hungary) 1981.

7. Ekblom A, Flock A, Hansson P, Ottosson D. Ultrastructural and electrophysiological changes in the olfactory epithelium following exposure to organic solvents. Acta Otolaryngol 98 (1984) 351-361.
8. Elofsson S-A, Gamberale F, Hindmarsh T, lregren A, Isaksson A, Johnsson I, Knave B, Lydahl E, Mindus P, Persson HE, Philipsson B, Steby M, Struwe G, Söderman E, Wennberg A, Widén L. Exposure to organic solvents - A cross-sectional epidemiologic investigation on occupationally exposed car and industrial spray painters with special reference to the nervous system. Scand J Work Environ Health 6 (1980) 239-273.

9. Engen T. Psychophysics. In: Kling JW, Riggs LA, ed. Woodworth \& Schlosberg's experimental psychology. Methuen, London 1972, pp 11-86.

10. Engen T. The perception of odors. Academic press, New York, NY 1982, pp $21 \& 151$.

11. Engen T, Mair RG. Measuring deficits in odor perception. National Institute of Environmental Medicine, Stockholm 1983. (Report no 8/1983).

12. Graziadei PPC, Graziadei GAM. Continuous nerve renewal in the olfactory nerve system. In: Jacobson M, ed. Handbook of sensory physiology. Volume IX (Development of sensory systems). Springer Verlag, New York, NY 1978, pp 55-83.

13. Harris D, Haines $H$, Myers C. Loudness perception for pure tones and for speech. Arch Otolaryngol 55 (1952) 107-133.

14. Laing DG, Panhuber K. Neural and behavioral changes in rats following continuous exposure to an odor. J Comp Physiol Psychol 124 (1978) 259-265.

15. Lane HL, Catania AC, Stevens SS. Voice level: Autophonic scale, perceived loudness and effect of sidetone. J Acoust Soc Am 33 (1961) 160-167.

16. Lindvall $\mathrm{T}$. On sensory evaluation of odorous air pollutant intensities. Nord Hyg Tidskr (1970): suppl 2, $1-181$.

17. Lowe HI, Hagler K. Determination of volatile organic anaesthetics in blood, gases, tissues and lipids: Partition coefficients. In: Porter R, ed. CIBA Foundation symposium on gas chromatography in biology and medicine. Churchill Ltd, London 1969, pp 86-103.

18. Mikkelsen S, Gregersen P, Klaussen H, Dössing M, Nielsen $\mathrm{H}$. Praesenil demens som erhvervssygdom ved industriel eksposition for organiske oplösningsmidler. En litteraturgennemgang [Presenile dementia as a symptom caused by exposure to organic solvents at industrial work: A review of the literature]. Ugeskr Læg 140 (1978) 1633-1638.

19. Moskowitz HR, Dravnieks A, Cain WS, Turk A. Standardized procedure for expressing odor intensity. Chem Senses Flavor 1 (1974) 235-237.

20. Pinching AJ, Döving KB. Selective degeneration in the rat olfactory bulb following exposure to different odours. Brain. Res 82 (1974) 195-204.

21. Scharf B: Loudness. In: Carterette E, Friedman M, ed. Handbook of perception. Volume IV. Academic Press, New York, NY 1978, pp 187-242.

22. Stahl WH, ed. Compilation of odor and taste threshold values data. American Society for Testing and Materials, Philadelphia, PA 1973. (ASTM data series DS 48).

23. Stevens SS. Psychophysics. Wiley, New York, NY 1975.

24. Swedish National Board of Occupational Safety and Health. 1981: 8: Occupational standards. Liber Förlag, Stockholm 1981.

25. Wonnacott TH, Wonnacott RJ. Introductory statistics. Third edition. Wiley, New York, NY 1977.

26. Woodworth RS, Schlosberg HS. Experimental psychology. Holt, New York, NY 1954.

Received for publication: 11 November 1986 